\title{
Mechanical Properties and Microstructural Characterization of Dissimilar Friction Stir Welded AA5083 and AA6061 Aluminium Alloys
}

\author{
Sasi Lakshmikhanth RAJASEELAN*, Subbaiah KUMARASAMY** \\ *Department of mechanical engineering, SSN college of Engineering, Anna University, Chennai, India, \\ E-mail: rslkhanth@gmail.com \\ **Department of mechanical engineering, SSN college of Engineering, Anna University, Chennai, India, \\ E-mail:subbaiahk@ssn.edu.in
}

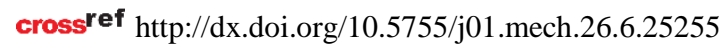

\section{Introduction}

Fusion welding of dissimilar aluminium alloys produces solidification cracking in the weld zone. This can be avoided by careful selection of filler material mostly based on the material composition. But in most cases, there is no filler material available for the joining of dissimilar grade of aluminium alloys. So, industries recommend solid state welding process as suitable joining method for joining dissimilar grade of aluminium alloys [1-5].

Among the solid-state welding process, friction stir welding helps to overcome the solidification and liquification defects caused by conventional welding methods [6-9]. Friction stir welding is used to effectively join any combination of two dissimilar metals [10-15]. FSW combines material plastic strain and heat flow [16].

Aluminium alloys have many specific properties which created a very high demand for them in aerospace, marine and automotive industries [17]. Some good properties of aluminium are light weight, good corrosion resistance, good structural strength, high strength to weight ratio. The aluminium alloys AA5xxx (non-heat treatable) and AA6xxx (heat treatable) are used in the fabrication of aircraft and ship structural members [18]. The welding of two different grades of aluminium (heat treatable and nonheat treatable aluminium alloys) is used in marine applications for achieving high corrosion resistance and high strength to weight ratio. AA5083-H111 is corrosion resistant, so it is used in ship hull structures exterior area that is exposed to the sea, whereas AA6061-T6 has good strength, therefore it is used in the interior structural development of the ship hull which is not exposed to the sea water [19].

In this regard, the joining of dissimilar aluminium (5xxx and 6xxx) series was investigated experimentally by various researchers. Hector et al., [20] had reported that it is possible to join dissimilar aluminium alloys using friction stir processing with higher tensile strength. Jitender Kundu et al. [21] had done similar friction stir welding on a $4.5 \mathrm{~mm}$ thick AA5083-H321 plate to find out optimum welding parameter (tool rotational speed and tool traverse speed) to make a defect free joint. They had conducted experiments using various welding parameters (tool rotation speeds $-500,950$ and $1400 \mathrm{rpm}$; tool traverse speeds - 16, 28 and $40 \mathrm{~mm} / \mathrm{min}$ ) and have concluded that $950 \mathrm{rpm}$ tool rotational speed and $28 \mathrm{~mm} / \mathrm{min}$ tool traverse speed as the optimum value to obtain a defect free weld with higher UTS and higher micro-hardness values.
Palanivel et al., [22] had done dissimilar friction stir welding on $6 \mathrm{~mm}$ thick AA5083 and AA6351 plates using five different tool pin profile shapes (straight cylindrical, threaded cylindrical, straight square, tapered square, and tapered octagon) and have concluded that the weld obtained by using the straight square pin profile showed good mechanical properties compared to the other tool pin profile. Rodrigues et al., [23] has conducted dissimilar friction stir welding experiments on AA5083-H111 and AA6082-T6 aluminium alloys with various tool parameters and various welding parameters and has concluded that to obtain a defect free weld, tool shoulder diameter is an important criterion, if the tool shoulder diameter is very small for a thick plate welding with low tool tilt angle then defects will occur in the weld. They also stated that for high tool rotational speeds tool parameters becomes relatively less dependent.

Tevfik Kucukomeroglu et al., [24] carried out dissimilar friction stir welding on AA5754 and AA6061 by keeping the tool geometry and tool tilt angle constant and by varying tool rotational speed, tool traverse speed and tool press force. They have concluded that using friction stir welding a defect free weld is obtained and the Heat Affected Zone (HAZ) of the 6061 side is observed as the weakest zone in the weld.

The present work depicts the dissimilar joining of 5 mm thick AA5083-H111 (non heat-treatable) and AA6061-T6 (heat-treatable) aluminium alloys. An experimental analysis of the mechanical properties and the material flow pattern of the joints were analyzed across the weld nugget zone of samples.

\section{Experimental procedure}

The base metals AA5083-H111 (Non heattreatable) and AA6061-T6 (heat-treatable) alloy of $5 \mathrm{~mm}$ thick are cut into pieces of $150 \mathrm{~mm} \times 75 \mathrm{~mm}$ dimensions. The chemical composition (wt. \%) of the AA5083-H111 and AA6061-T6 aluminium alloys are given in Table 1. The mechanical properties of the base metals used in this study are given in Table 2. In this study, dissimilar friction stir welding is carried out by placing the non heat-treatable alloy AA5083-H111 on the advancing side and the heattreatable alloy AA6061-T6 on the retreating side. The welding parameters used to carry out the dissimilar friction stir welding are given in Table 3. The experiment was carried out in a friction stir welding machine (Make: M/S Creative automations, Coimbatore, India). The specification of machine is as follows, maximum spindle speed - 
$3000 \mathrm{rpm}$, maximum power - $30 \mathrm{hp}$ and maximum axial force $-25 \mathrm{kN}$. The tensile specimens were extracted along the transverse direction of the weld using the EDM wire cutting machine. The specimens were prepared according to ASTM-E8 standards. Small samples were extracted along the transverse direction of the dissimilar friction stir welded plate to characterize the microstructures and the hardness values. Tensile strength, yield strength and \% elongation were found out in the samples by using the Universal Testing Machine (UTM) (Bluestar make, model LDW 50).
Vickers microhardness tester (ESEWY make, Model EW-423DAP) was used to evaluate the hardness values across the various zones of the Friction Stir Welded samples with an equiaxed distance of $0.5 \mathrm{~mm}$ by applying $0.5 \mathrm{~kg}$ load with a dwell time of $15 \mathrm{sec}$.

Keller reagent was used to reveal the microstructure of the specimen. The microstructural analyses were carried out using both optical microscope and scanning electron microscope (Carl ZEISS make, model EVO 18 research). The elemental analysis was carried out using SEM-EDX to find out the precipitates present in the welded sample.

Table 1

Chemical composition (wt. \%) of the base materials

\begin{tabular}{|c|c|c|c|c|c|c|c|c|c|}
\hline Base Metal & $\mathrm{Mg}$ & $\mathrm{Mn}$ & $\mathrm{Fe}$ & $\mathrm{Si}$ & $\mathrm{Cu}$ & $\mathrm{Cr}$ & $\mathrm{Zn}$ & $\mathrm{Ti}$ & $\mathrm{Al}$ \\
\hline AA5083-H111 & 4.254 & 0.525 & 0.259 & 0.980 & 0.346 & 0.113 & 0.103 & 0.019 & 93.31 \\
\hline AA6061-T6 & 0.812 & 0.061 & 0.323 & 3.01 & 1.142 & 0.184 & 0.072 & 0.02 & 94.31 \\
\hline
\end{tabular}

Table 2

Mechanical properties of base materials

\begin{tabular}{|c|c|c|c|c|}
\hline Base material & HV1 & UTS, MPa & Yield Strength, MPa & Elongation (\%) \\
\hline AA 5083-H111 & 80 & 321.34 & 197.39 & 22.26 \\
\hline AA 6061-T6 & 115 & 325.08 & 265.99 & 15.93 \\
\hline
\end{tabular}

Table 3 H111 base metal has fine grain structure, whereas in the

Welding process parameters and tool properties

\begin{tabular}{|l|l|}
\hline Process parameters & Values \\
\hline Tool rotational speed $R P M$ & 950 \\
\hline Tool traverse speed, $\mathrm{mm} / \mathrm{min}$ & 28 \\
\hline Tool pin profile & Straight square \\
\hline$D / d$ ratio of the tool & 3.0 \\
\hline Tool shoulder diameter $D, \mathrm{~mm}$ & 15 \\
\hline Tool pin diameter $d, \mathrm{~mm}$ & 5 \\
\hline Tool pin length, $\mathrm{mm}$ & 4.5 \\
\hline
\end{tabular}

\section{Results}

\subsection{Optical microscopy (OM)}

The optical microscopy images of the dissimilar friction stir welded AA5083-H111 and AA6061-T6 aluminium alloys at $100 \mathrm{X}$ magnification is shown in Fig. 1. The microstructure of AA5083-H111 base metal is shown in Fig. 1, a and the microstructure of AA6061-T6 base metal is shown in Fig. 1, b. Large number of dark spots are observed in Fig. 1, a. It shows the presence of large quantity of strengthening precipitates in the AA5083 base metal. The grain boundaries are not clearly visible in AA5083H111 aluminium alloy, whereas in case of AA6061-T6 aluminium alloy base metal microstructure (Fig. 1, b) the grain boundaries are clearly visible. It is noticed that the grains of AA6061-T6 are oriented along the rolling direction of the plates. The dark particles that were observed in the Fig. 1, b, shows the presence of the major strengthening precipitate of AA6061-T6 $\left(\mathrm{Mg}_{2} \mathrm{Si}\right)$. A large number of $\mathrm{Mg}_{2} \mathrm{Si}$ precipitates can be found in the AA6061-T6 alloy with various morphologies. Some $\mathrm{Mg}_{2} \mathrm{Si}$ precipitates are in round shape, whereas few precipitates are found to be elongated along the rolling direction of the plate. These precipitates provide good tensile properties and high hardness values to the alloy. By comparing the microstructure of the base metal zone (Fig. 1, a) and heat affected zone (Fig. 1, c) of the AA5083-H111, it is clear that AA5083-
HAZ region of the AA5083-H111 side the grains have become coarser compared to the base metal grain structure. The grain growth has mainly occurred because of the heat flow in the HAZ region during the friction stir welding. When the microstructure of the base metal side (Fig. 1, b) and the HAZ of the AA6061-T6 side (Fig. 1, d) compared, it was clearly observed the grain growth in the HAZ region and the number of $\mathrm{Mg}_{2} \mathrm{Si}$ precipitates in the HAZ had been reduced. The increase in the grain size is one of the main reasons for the massive reduction in the tensile properties and the hardness value of the alloy according to the HallPetch equation. Another reason for the reduction in the hardness and tensile properties at the HAZ of the AA6061$\mathrm{T} 6$ side is the dissolution of the $\mathrm{Mg}_{2} \mathrm{Si}$ precipitates. Fig. 1, e shows the weld nugget zone where we can see the mixing of two materials. In the nugget zone we can see the grains have been broken down to finer grains, this is the reason for the increase in the hardness and tensile properties in the nugget zone.

\subsection{Scanning electron mcroscopy}

Fig. 2 shows the SEM images (2000X) at the various locations of the dissimilar friction stir welded AA5083-H111 and AA6061-T6. By comparing Fig. 2a (AA5083-H111 Base metal) and Fig. 2b (AA6061-T6 Base metal), the grain boundaries in the AA6061 side are clear whereas grain boundaries are not visible in the AA5083 side. Also, a large amount of precipitates in the AA5083 side was visible as there are many strengthening precipitates in AA5083-H111, whereas in AA6061 side very few precipitates are seen as there was only one strengthening precipitate $\left(\mathrm{Mg}_{2} \mathrm{Si}\right)$ in the AA6061-T6. The major strengthening precipitates that are present in AA5083$\mathrm{H} 111$ are $\mathrm{Al}_{6}(\mathrm{FeMn}), \mathrm{Al}_{3} \mathrm{Mg}_{2}, \mathrm{Al}_{6}(\mathrm{Fe}, \mathrm{Mn}) \mathrm{Cr}, \mathrm{Al}_{6}(\mathrm{FeMn}) \mathrm{Si}$ and $\mathrm{Mg}_{2} \mathrm{Si}$.

Comparing the base metal zone (Fig. 2, a) and the heat affected zone (Fig. 2, c) of the AA5083-H111 side, 
there was a reduction in the precipitate count in the heat affected zone. On comparing the base metal zone (Fig. 2, b) and the heat affected zone (Fig.2, d) of the AA6061-T6 side, the grain boundary growth was clear which was the reason for the reduction in the tensile properties according to Hall-Petch equation. In Fig. 2, e, we the mixing of two materials was clear and also the grain sizes are reduced to very small units. There is only a less amount of precipitates in the weld nugget zone, mainly because most of the precipitates gets broken down due to the stirring made by the tool and many precipitates also gets dissolved due to the high heat in the weld nugget zone.
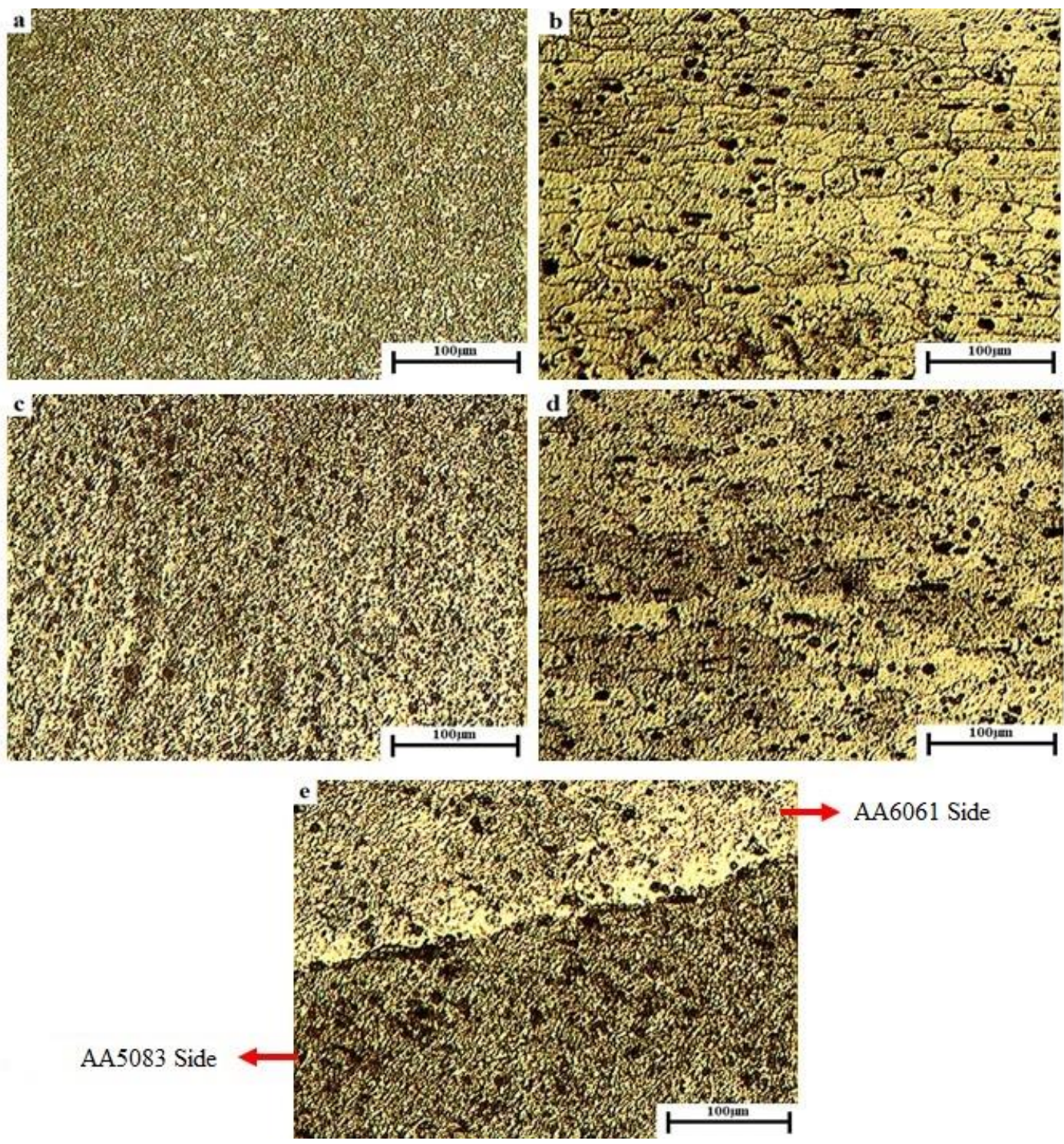

Fig. 1 OM images - 100X magnification a) 5083 BM; b) 6061 BM; c) 5083 HAZ; d) 6061 HAZ; e) weld nugget

\subsection{SEM - EDX analysis}

EDX (Energy Dispersive X-Ray) analysis was done on the weld nugget zone of the dissimilar friction stir welded AA5083-H111 and AA6061-T6 and the EDX was taken in the spots shown in Fig. 3. Five spots were taken on the precipitates present in the nugget zone and the elements present on the EDX spots are shown in Table 4. It can be seen in the Table 4 that the presence of Magnesium $(\mathrm{Mg})$ is very low. The quantity of magnesium (weight \%) in the base metals are $4.25 \%$ in the AA5083-H111 and $0.81 \%$ in the AA6061-T6, but in the nugget zone the average magnesium content is only $0.39 \%$. The reduction in the magnesium content is mainly because of the dissolution that has occurred due to the heat caused by friction stir welding. The precipitates present in the weld nugget zone of dissimilar friction stir welded are shown in Table 4. The major strengthening precipitates of AA6061-T6 $\left(\mathrm{Mg}_{2} \mathrm{Si}\right)$ are completely dissolved in the nugget zone because of the heat produced during the dissimilar friction stir welding. This made the HAZ of AA6061-T6 the softer zone and caused the failure to occur in this zone.

\subsection{Tensile properties}

The tensile properties of dissimilar friction stir welded joints of $5 \mathrm{~mm}$ thick non-heat treatable AA5083H111 and heat treatable AA6061-T6 aluminium alloy plates were listed in Table 5. It was clear from the tensile study that the tensile strength of the weld was less than that of the base metal strength. The tensile sample of dissimilar friction stir welded AA5083-H111 and AA6061-T6 is shown in Fig. 4. It can also be noted from the Fig. 4 that the fracture location for both the tensile samples were observed at the heat affected zone of the 6061-T6 side of the weld. The average ultimate tensile strength of the dissimi- 
lar friction stir welded joint is $185.5 \mathrm{MPa}$ which is $57.94 \%$ the strength of the weaker base metal ultimate tensile strength. The average $\%$ elongation of the welded sample is 12.25 which is $76.9 \%$ of the weaker base metal \% elongation. Fig. 4, b shows the side view of the tensile samples.

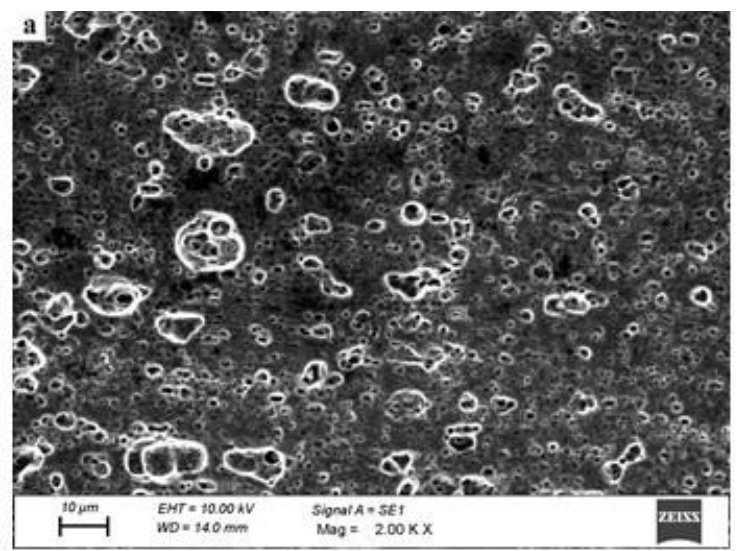

In these samples it was clear that the fracture has taken place at $45^{\circ}$ inclined angle at the HAZ of the 6061-T6 side. The HAZ of the AA6061-T6 side is considered as the weakest zone in the dissimilar friction stir welded AA5083-H111 and AA6061-T6 sample.
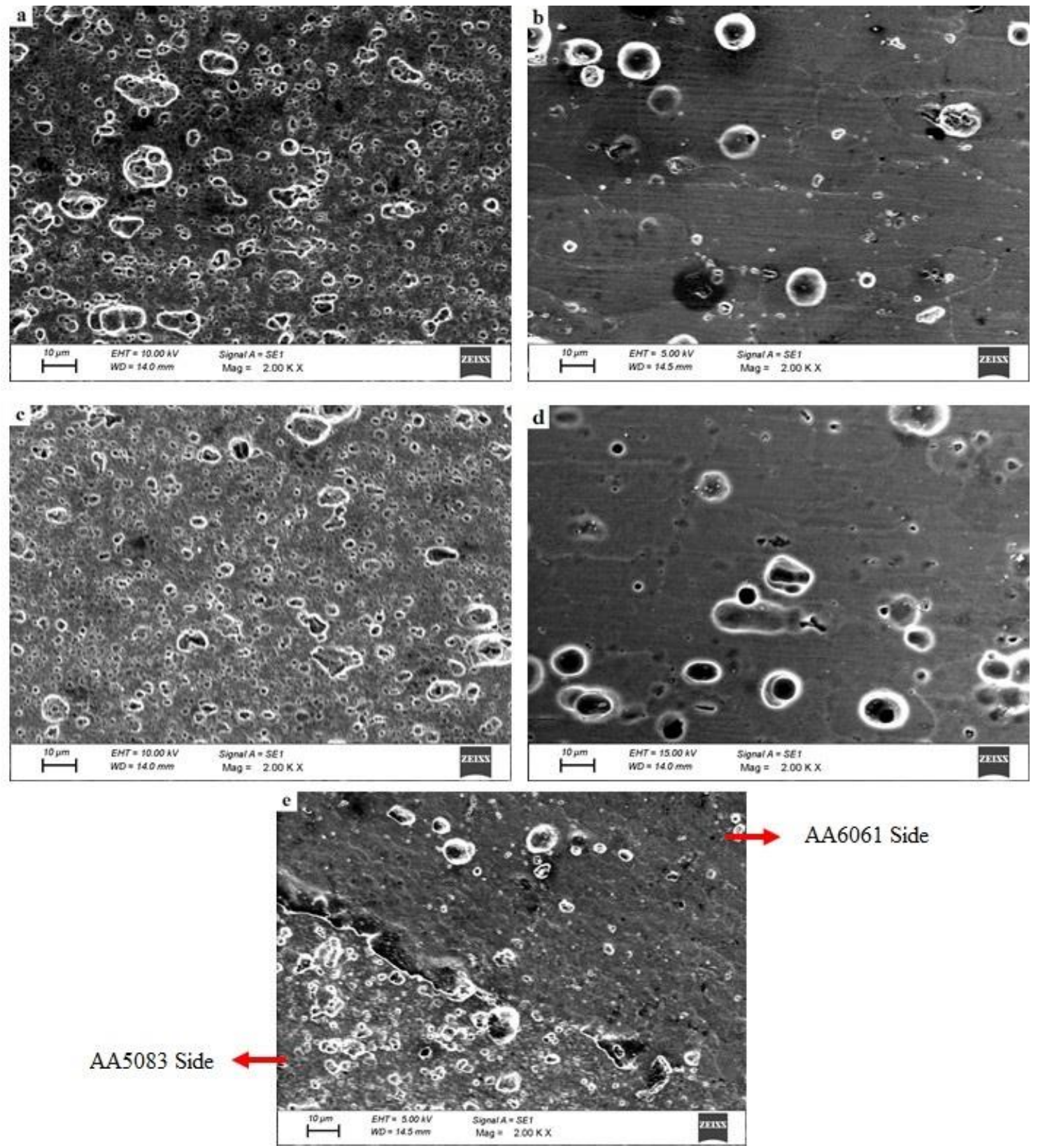

Fig. 2 SEM images - 2000X magnification a) 5083 BM; b) 6061 BM; c) 5083 HAZ; d) 6061 HAZ; e) weld nugget

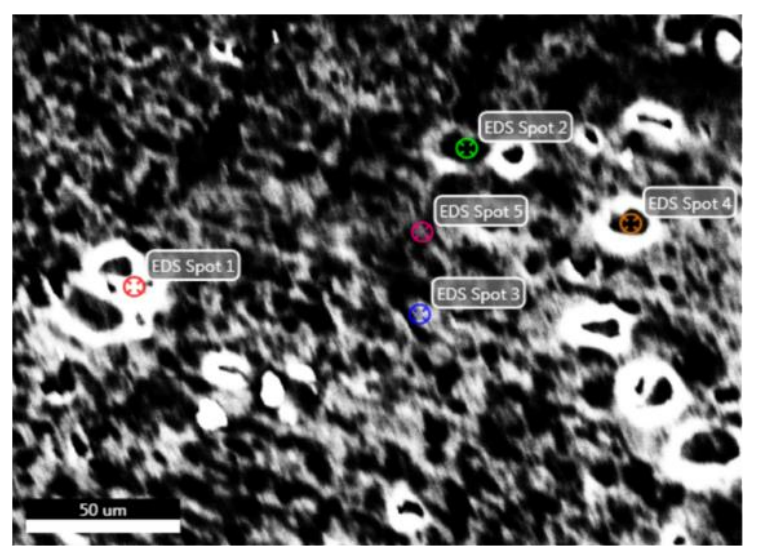

Fig. 3 SEM EDX spots in weld nugget at $2000 \mathrm{X}$ magnification 
Table 4

SEM-EDX showing the alloying elements (weight \%) in the weld nugget zone

\begin{tabular}{|c|c|c|c|c|c|c|}
\hline & $\mathrm{Al}$ & $\mathrm{Mg}$ & $\mathrm{Mn}$ & $\mathrm{Cr}$ & $\mathrm{Fe}$ & $\mathrm{Si}$ \\
\hline Spot 1 & 87.15 & 0.19 & 2.34 & 2.86 & 3.42 & 4.03 \\
\hline Spot 2 & 89.3 & 0.77 & 2.68 & 2.55 & 3.52 & 1.19 \\
\hline Spot 3 & 89.07 & 0.66 & 1.51 & 2.7 & 4.62 & 1.44 \\
\hline Spot 4 & 89.92 & 0.21 & 2.94 & 1.64 & 4.13 & 1.17 \\
\hline Spot 5 & 88.97 & 0.13 & 1.44 & 3.05 & 4.28 & 2.13 \\
\hline Avg & 88.88 & 0.39 & 2.18 & 2.56 & 3.99 & 1.99 \\
\hline
\end{tabular}

Table 5

Tensile properties of dissimilar friction stir welded joints

\begin{tabular}{|c|c|c|c|}
\hline FSW Samples & UTS (MPa) & El (\%) & Fracture Location \\
\hline Sample 1 & 185 & 11.50 & At HAZ of 6061 side of the Weld \\
\hline Sample 2 & 186 & 13.00 & At HAZ of 6061 side of the Weld \\
\hline Average Value & 185.5 & 12.25 & \\
\hline
\end{tabular}

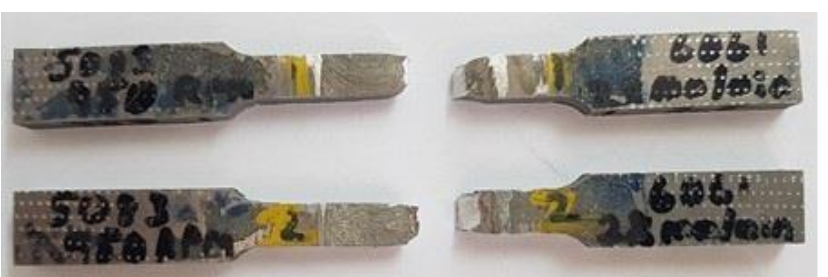

a

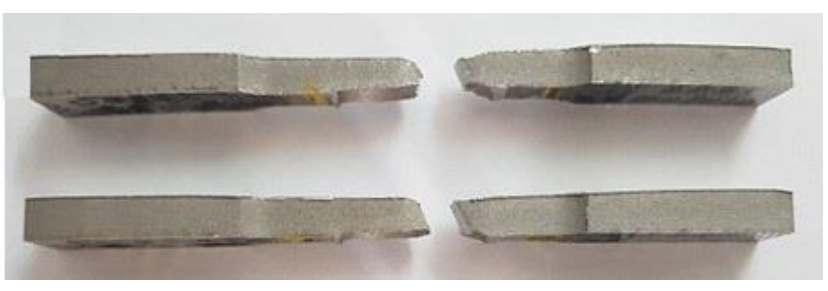

b

Fig. 4 Fracture location of tensile specimens a) front view; b) side view

\subsection{Hardness survey}

The graph below shows the microhardness profile of dissimilar friction stir weld of non heat-treatable, AA5083-H111 and heat-treatable AA6061-T6 aluminium alloys with $950 \mathrm{RPM}$ and $28 \mathrm{~mm} / \mathrm{min}$. It should be noted that the hardness profile on the advancing (AA5083-H111) side is almost identical. In the advancing side the average grain size of the TMAZ and HAZ is higher than that of the grain size in the weld nugget, but there is only a modest increase in the hardness of the stir zone compared to the hardness of the TMAZ. This occurs mainly due to the presence of precipitates in the TMAZ.

It can be seen clearly in the Fig. 5 that the highest hardness values were observed at the base metal side of AA6061-T6 aluminium alloy; this is because of the presence of a large number of $\mathrm{Mg}_{2} \mathrm{Si}$ precipitates. It was clear that there is a huge drop in the hardness value in the heat affected zone of the AA6061-T6 side, this is because, the main strengthening precipitate present in the AA6061-T6 $\left(\mathrm{Mg}_{2} \mathrm{Si}\right)$ base metal gets dissolved due to the heat that occurs during the friction stir welding. The dissolving of the $\mathrm{Mg}_{2} \mathrm{Si}$ precipitates causes reduction in hardness and the strength in the HAZ of the 6061 side, which makes it the weakest spot in the weld. The imposed thermal cycles and severe plastic deformation on the TMAZ of the AA6061 side lead to the elimination of precipitate hardening and hence there is a drop in the hardness in the TMAZ. It was also evident from the figure that the hardness in the weld nugget of the FS welded AA5083 and AA6061 was higher than the base metal hardness of the AA5083-H111, this is because of the grain size refinements and dynamic recrystallization in the stir zone. The tool pin profile is the main reason for the proper dynamic recrystallization. As the grain size in the weld nugget is small due to the recrystallization, the hardness value in the weld nugget is higher as per the Hall-Petch equation.

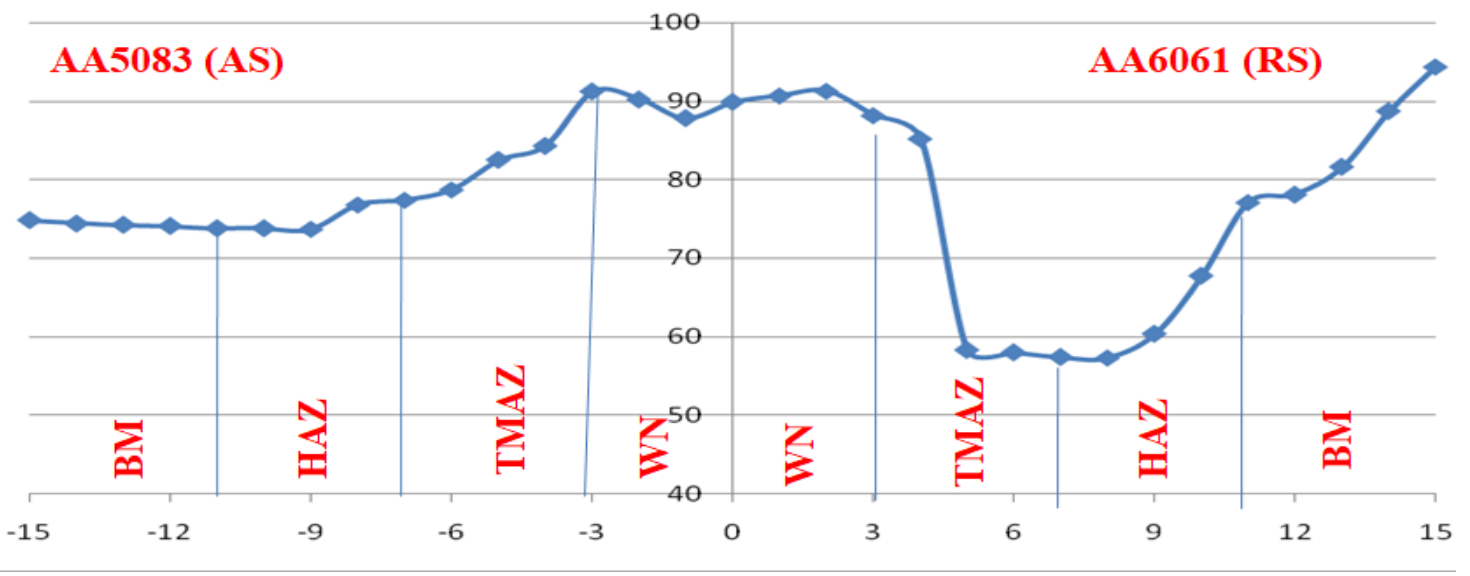

Fig. 5 Hardness plot of dissimilar FSWed AA5083-H111 and AA6061-T6 


\section{Discussion}

From the samples obtained from the welded joints of AA5083-H111 and AA6061-T6 it is clear that a defect free welding can be done by using friction stir welding. In friction stir welding the heat required to do the joining is achieved by the friction occurring between the tool and the base materials. The heat input given influences the material flow from the advancing side to the retreating side and vice versa. The main factors influencing the heat input are the tool rotational speed and the welding speed. Another important factor which influence the material flow is the tool pin profile, because the tool carries the material from the advancing side to the retreating side with the front end and from retreating side to advancing side with the rear end. If the material flow from the retreating side to the advancing side is less than the material flow from advancing side to retreating side, then a void occurs and creates a defect in the weld nugget. If the heat input is very high, then turbulent flow of materials occurs and it will also result in defects. So it is very important to get an optimum welding parameters and tool pin profile to achieve a defect free friction stir welds.

The top portion of the stir zone is the shoulder influenced region, the material flow in this region is due to the heat generated by the rotation and rubbing of tool shoulder with the work piece during FSW. The bottom portion of the stir zone is the pin influenced region, the material flow in this region is due to the heat generated by the rotation and rubbing of tool pin with the dissimilar materials.

\subsection{Effect of microstructure on tensile properties}

The mechanical properties of the weld is determined by the local microstructure, so in order to determine the global joint strength the relationship between the microstructure and mechanical property is crucial. The welded joint microstructure is formally divided into three zones [25], they are Weld Nugget (WN), Thermo-mechanically Affected Zone (TMAZ) and Heat Affected Zone (HAZ). The weld nugget or the stirred zone consists of fineequiaxed recrystallized grains that are formed due to high temperature and high deformation rate in the weld nugget due to the stirring caused by the tool pin [26]. Bent elongated grains can be observed near the nugget which is the TMAZ [27]. The zone next to the TMAZ is the HAZ, this zone will experience thermal cycle, but will not undergo any plastic deformation. In the HAZ the grain size will be same as that of the base material. The grain growth in the HAZ is caused mainly by the thermal exposure.

The average UTS of the dissimilar friction stir welded joint is $185.5 \mathrm{MPa}$ which is $57.94 \%$ of the weaker base metal AA5083-H111. Ilangovan et.al. [19] has done dissimilar friction stir welding between AA6061 and AA5086 and has achieved the UTS value of $140 \mathrm{MPa}$ which is $56 \%$ compared to the weaker base metal AA5086$\mathrm{O}$. In this study, the fracture in the dissimilar welded sample was observed in the HAZ of the AA6061-T6 side. The heat flow in the HAZ during the dissimilar friction stir welding resulted in the dissolution of the $\mathrm{Mg}_{2} \mathrm{Si}$ precipitates, which is the main strengthening precipitate in the AA6061-T6 aluminium alloy. The friction stir welding process is a solid state welding process. The temperature during DFSW joint is approximately $500^{\circ} \mathrm{C}$. The aluminium alloy melting temperature is around $650^{\circ} \mathrm{C}$. $\mathrm{The}_{\mathrm{Mg}_{2} \mathrm{Si}}$ precipitate which is the main precipitate responsible for precipitation hardening in AA6061 aluminium alloy dissolves at $450^{\circ} \mathrm{C}$. Gurel Cam et al [28]. has done friction stir welding on AA6061-T6 with and without AA7075-T6 interlayer and has obtained a weld joint efficiency of $59.3 \%$ for similar FSW joint and $59.37 \%$ for similar FSW joint with AA7075-T6 interlayer.

\subsection{Effect of hardness on tensile properties}

From the hardness survey the lowest hardness was observed in the TMAZ/HAZ of the AA6061-T6 side. The specimen broke in conformity with the hardness survey, in the TMAZ/HAZ of the precipitation hardened alloy AA6061-T6. The HAZ of the AA6061-T6 is considered as the soft region of the welded sample. During tensile loading, the fracture occurs in the soft region, which is the weakest point of the sample [29]. In a dissimilar welded joint, the strength of the specimen is mainly dependent on the mechanical interlocking of the materials than their metallurgical bonding. The mechanical interlocking is improved by the features like interpenetrating features, chaotic flow and the longer interface layer [30].

The hardness distribution in the FSW joint is based on brittle intermetallic formation, precipitate formation, strain hardening and boundary energy. The increase in grain boundaries and the reduction in grain size due to dynamic recrystallization of grains caused by the tool pin profile results in the high hardness values at the weld nugget of the dissimilar joint. According to HallPetch relationship the grain size is inversely proportional to the hardness and the strength of the joints. In case of the precipitation hardenable alloys, the precipitate formation shows a significant effect on the tensile properties compared to the grain size effects. For heat treatable alloys, the strength and the hardness values mainly depends on the distribution and the availability of the precipitates [31]. During welding of the heat treatable aluminium alloys the precipitates present in the alloys gets dissolved due to the flow of heat, which results in the reduction of strength. On aging, the precipitates are slowly formed which increases the strength of the aluminium alloy [32]. Since AA6061T6 is a heat treatable aluminium alloy, the $\mathrm{Mg}_{2} \mathrm{Si}$ precipitates which are present in the AA6061 gets dissolved due to the heat flow during welding which makes it the weakest spot, but after age hardening the $\mathrm{Mg}_{2} \mathrm{Si}$ precipitates will form again in the alloy which will result in the increased strength and hardness.

\section{Conclusions}

A dissimilar friction stir welding of AA5083H111 and AA6061-T6 was successfully conducted with no major defects inside the weld. The conclusions from the study conducted are as follows:

1. from the microstructure images obtained from the Optical Microscopy and Scanning Electron Microscopy we can conclude that the weakest spot in the dissimilar friction stir welded sample is the heat affected zone (HAZ) of the AA6061-T6 side because of the grain growth that occurred in this zone; 
2. from the Energy Dispersive X-Ray (EDX) analysis on the weld nugget zone of the dissimilar friction stir welded sample we can clearly see the huge reduction in weight percentage of magnesium particles, this shows that the $\mathrm{Mg}_{2} \mathrm{Si}$ particles has dissolved in the weld nugget due to the heat input during FSW;

3. the tensile strength obtained in the dissimilar friction stir welding of AA5083-H111 and AA6061-T6 was $186 \mathrm{MPa}$ with a weld joint efficiency of $58 \%$ compared to the weaker base metal tensile strength. The failure has occurred at the heat affected zone (HAZ) of the AA6061-T6 side;

4. high hardness values were obtained in the weld nugget zone due to the presence of fine equiaxed recrystallized grain that occurred because of the proper stirring made by the tool pin, and a very low hardness value was obtained at the HAZ of the 6061 side because of the dissolution of $\mathrm{Mg}_{2} \mathrm{Si}$ precipitates.

\section{References}

1. Khodir, S. A.; Shibayanagi, T. 2008. Friction stir welding of dissimilar AA2024 and AA7075 aluminium alloys, Materials Science and Engineering B 148: 8287.

https://doi.org/10.1016/j.mseb.2007.09.024.

2. Koilraj, M.; Sundareswaran, V.; Vijayan, S.; Koteswara Rao, S. R. 2012. Friction stir welding of dissimilar aluminum alloys AA2219 to AA5083 - Optimization of process parameters using Taguchi technique, Materials and Design 42: 1-7.

https://doi.org/10.1016/j.matdes.2012.02.016.

3. Cavaliere, P.; De Santis, A.; Panella, F.; Squillace A. 2009. Effect of welding parameters on mechanical and microstructural properties of dissimilar AA6082AA2024 joints produced by friction stir welding, Materials and Design 30: 609-616. https://doi.org/10.1016/j.matdes.2008.05.044.

4. Bala Srinivasan, P.; Dietzel, W.; Zettler, R.; dos Santos, J. F.; Sivan, V. 2005. Stress corrosion cracking susceptibility of friction stir welded AA7075AA6056 dissimilar joint, Materials Science and Engineering A 392: 292-300.

https://doi.org/10.1016/j.msea.2004.09.065.

5. Amancio-Filho, S. T.; Sheikhi, S.; dos Santos, J. F.; Bolfarini, G. 2008. Preliminary study on the microstructure and mechanical properties of dissimilar friction stir welds in aircraft aluminium alloys 2024-T351 and 6056-T4, Journal of Materials Processing Technology 206: 132-142.

https://doi.org/10.1016/j.jmatprotec.2007.12.008.

6. Yan, Y.; Zhang, Da-tong.; Qiu, Cheng.; Zhang, Wen. 2010. Dissimilar friction stir welding between 5052 aluminum alloy and AZ31 magnesium alloy, Transactions of Nonferrous Metals Society of China 20: 619-623.

https://doi.org/10.1016/s1003-6326(10)60550-x.

7. Xue, P.; Ni, D. R.; Wang, D.; Xiao, B. L.; Ma, Z.Y. 2011. Effect of friction stir welding parameters on the microstructure and mechanical properties of the dissimilar Al-Cu joints, Materials Science and Engineering A 528: 4683-4689.

https://doi.org/10.1016/j.msea.2011.02.067.
8. Kah, P.; Hiltunen, E.; Martikainen, J.; Katajisto, J. 2009. Experimental investigation of welding of aluminum alloy profiles and wrought plate by FSW, Mechanika 79: 21-27.

9. Shanmuga Sundaram, N.; Murugan, N. 2009. Dependence of ultimate tensile strength of friction stir welded AA2024-T6 aluminium alloy on friction stir welding process parameters, Mechanika 78: 17-24.

10. Kwon, Y.J.; Shigematsu, I.; Saito, N. 2008. Dissimilar friction stir welding between magnesium and aluminum alloys, Materials Letters 62: 3827-3829. https://doi.org/10.1016/j.matlet.2008.04.080.

11. Chen, Yu-hua; Ni, Quan; Ke, Li-ming. 2012. Interface characteristic of friction stir welding lap joints of Ti/Al dissimilar alloys, Transactions of Nonferrous Metals Society of China 22: 299-304. https://doi.org/10.1016/S1003-6326(11)61174-6.

12. Kwon, Yong-Jai; Shim, Seong-Beom; Park, DongHwan. 2009. Friction stir welding of 5052 aluminum alloy plates, Transactions of Nonferrous Metals Society of China 19: 23-27. https://doi.org/10.1016/S1003-6326(10)60239-7.

13. Jamshidi Aval, H.; Serajzadeh, S.; Kokabi, A. H.; Loureiro, A. 2011. Effect of tool geometry on mechanical and microstructural behaviors in dissimilar friction stir welding of AA5086-AA6061, Science and Technology of Welding and Joining 16: 597-604. https://doi.org/10.1179/1362171811Y.0000000044.

14. Mohammad Mahdi Moradi; Hamed Jamshidi Aval; Roohollah Jamaati. 2018. Microstructure and texture evolution of friction stir welded dissimilar aluminum alloys: AA2024 and AA6061, Journal of Manufacturing Processes 32: 1-10. https://doi.org/10.1016/j.jmapro.2018.01.016.

15. Mohammad Mahdi Moradi; Hamed Jamshidi Aval; Roohollah Jamaati. 2017. Microstructure and mechanical properties in nano and microscale SiC included dissimilar friction stir welding of AA6061-AA2024, Materials Science and Technology: 1-14. https://doi.org/10.1080/02670836.2017.1393976.

16. Genevois, C.; Deschamps, A.; Denquin, A.; Doisneau-cottignies, B. 2005. Quantitative investigation of precipitation and mechanical behavior for AA2024 friction stir welds, Acta Materialia 53: 2447-2458. https://doi.org/10.1016/j.actamat.2005.02.007.

17. Jamshidi Aval, H.; Serajzadeh, S.; Kokabi, A. H. 2011. Evolution of microstructures and mechanical properties in similar and dissimilar friction stir welding of AA5086 and AA6061, Materials Science and Engineering A 528: 8071-8083.

https://doi.org/10.1016/j.msea.2011.07.056.

18. Luijendijk, T. 2000. Welding of dissimilar aluminium alloys, Journal of Materials Processing Technology 103: 29-35. https://doi.org/10.1016/S0924-0136(00)00415-5.

19. Ilangovan, M.; Rajendra Boopathy, S.; Balasubramanian, V. 2015. Microstructure and tensile properties of friction stir welded dissimilar AA6061-AA5086 aluminium alloy joints, Transactions of Nonferrous Metals Society of China 25: 1080-1090. https://doi.org/10.1016/S1003-6326(15)63701-3.

20. Louis, G;. Hector, Jr.; Yen-Lung, Chen.; Sumit Agarwal; Clyde L. Briant. 2007. Friction stir processed AA5182-O and AA6111-T4aluminum alloys. 
Part 2: Tensile properties and strain field evolution, Journal of Materials Engineering and Performance 16: 404-417.

https://doi.org/10.1007/s11665-007-9060-0.

21. Jitender Kundu; Hari Singh. 2016. Friction stir welding of AA5083 aluminium alloy: Multi-response optimization using Taguchi-based grey relational analysis, Advances in Mechanical Engineering 8: 1-10. https://doi.org/10.1177/1687814016679277.

22. Palanivel, R.; Koshy Mathews, P.; Murugan, N. 2010. Influence of tool pin profile on the mechanical and metallurgical properties of friction stir welding of dissimilar aluminium alloy, International Journal of Engineering Science and Technology 2: 2109-2115.

23. Rodrigues, D. M.; Leitao, C.; Louro, R.; Gouveia, H.; Loureiro, A. 2010. High speed friction stir welding of aluminium alloys, Science and Technology of Welding and Joining 15: 676-681. https://doi.org/10.1179/136217110X12785889550181.

24. Kucukomeroglu, T.; Yilmaz, H.; Aktarer, S. M. 2013. The effect of tool press force to weldability of AA5754 and AA6061 alloys with friction stir welding method, Pamukkale University Journal of Engineering Sciences 19: 281-286. https://doi.org/10.5505/pajes.2013.92408.

25. Lomolino, S.; Toyo, R.; Dos Santos, J. 2005. On the fatigue behavior and design curves of friction stir butt welded Al alloys, International Journal of Fatigue 27: 305-316. https://doi.org/10.1016/j.ijfatigue.2004.06.013.

26. Kumar, K.; Satish V. Kailash. 2008. The role of friction stir welding tool on material flow and weld formation, Materials Science and Engineering A 485: $367-$ 374. https://doi.org/10.1016/j.msea.2007.08.013.

27. Yazdipour, A. R.; Shafiei, A. M.; Jamshidi Aval, H. 2011. An investigation of the microstructures and properties of metal inert gas and friction stir welds in aluminum alloys 5083, Sadhana 36: 505-514. https://doi.org/10.1007/s12046-011-0032-6.

28. Cam, G.; Ipekoglu, G.; Tarik Serindag, H. 2014. Effects of use of higher strength interlayer and external cooling on properties of friction stir welded AA6061T6 joints. Science and Technology of Welding and Joining 19: 715-720. https://doi.org/10.1179/1362171814Y.0000000247.

29. Moreira, P. M. G. P.; Santos, T.; Tavares, S. M. O.; Richter-Trummer, V.; Vilaca, P.; de Castro, P. M. S. T. 2009. Mechanical and metallurgical characterization of friction stir welding joints of AA6061-T6 with AA6082-T6, Materials and Design 30: 180-187. https://doi.org/10.1016/j.matdes.2008.04.042.

30. Venkateswaran, P.; Reynolds, A. P. 2012. Factors affecting the properties of friction stir welds between aluminum and magnesium alloys, Materials Science and Engineering A 545: 26-37.

https://doi.org/10.1016/j.msea.2012.02.069.

31. Gurel Cam.; Guven Ipekoglu. 2017. Recent developments in joining of aluminum alloys, International Journal of Advanced Manufacturing Technology 91: 1851-1866.

https://doi.org/10.1007/s00170-016-9861-0.

32. Gallais, C.; Denquin, A,; Brechet, Y.; Lapasset, G. 2008. Precipitation microstructures in an AA6056 aluminium alloy after friction stir welding: Characterization and modeling, Materials Science and Engineering A 496: 77-89. https://doi.org/10.1016/j.msea.2008.06.033.

\section{S. L. Rajaseelan, S. Kumarasamy}

\section{MECHANICAL PROPERTIES AND \\ MICROSTRUCTURAL CHARACTERIZATION OF DISSIMILAR FRICTION STIR WELDED AA5083 AND AA6061 ALUMINIUM ALLOYS}

S u m m a r y

Solidification is one of the major issues that was faced during the fusion welding of dissimilar non-heat treatable and heat treatable aluminium alloys. To overcome this issue Friction Stir Welding played a very vital role, since it is a solid state welding process. In current study, dissimilar friction stir welding was carried out between non heat-treatable aluminium alloy AA5083-H111 and heat-treatable aluminium alloy AA6061-T6. The microstructural analysis and the mechanical properties of the dissimilar friction stir welded aluminium alloy AA5083-H111 and AA6061-T6 have been investigated. Both optical microscopy and scanning electron microscopy was used to evaluate the microstructural features. The elemental analysis was carried out using SEM-EDX. The tensile properties are studied using Universal Testing Machine. Hardness at various zones of the welded joints was measured using Vicker's Hardness Testing Machine. The mechanical properties of the friction stir welded joints were correlated with the microstructure of the dissimilar welded joints.

Keywords: friction stir welding, AA5083-H111, AA6061T6, microstructure, SEM-EDX, fracture location, fractography, hardness.

Received February 08, 2020

Accepted December 01, 2020 